\title{
APLIKASI UJI KEBERFUNGSIAN DIFERENSIAL UNTUK MENGUJI KETAHANAN BUTIR SKALA PSIKOLOGI TERHADAP RESPONS TIPUAN PADA KONTEKS SELEKSI KERJA
}

\author{
Wahyu Widhiarso \\ Universitas Gadjah Mada Yogyakarta \\ email wahyu_psy@ugm.ac.id
}

\begin{abstract}
Abstrak: Penelitian ini bertujuan mengidentifikasi butir skala psikologi yang rentan terhadap respons tipuan ketika diaplikasikan pada seleksi pekerjaan. Skala kepribadian adaptasi dari BFI-44 diberikan kepada 400 responden yang terbagi menjadi dua kelompok. Kelompok pertama diinstruksikan untuk memberikan respons jujur (kondisi netral) sedangkan pada kelompok kedua diinstruksikan mereka seakan-akan aplikan yang tengah mengikuti tes seleksi pekerjaan (kondisi aplikan). Teknik analisis yang dipakai adalah uji keberfungsian butir (DIF) dengan uji Mantel-Haenzel. Dari analisis ditemukan 12 butir yang rentan terhadap respons tipuan yang tersebut tersebar pada empat faktor kepribadian (faktor ekstraversi, keramahan, kestabilan emosi dan keterbukaan terhadap gagasan baru). Dengan jumlah tersebut secara umum menunjukkan bahwa pengukuran psikologi yang menggunakan teknik pelaporan mandiri (self-report) cukup tahan terhadap respons tipuan. Namun demikian tetap perlu diadakan tinjauan ulang atau modifikasi terhadap butir-butir tersebut jika diaplikasikan pada proses seleksi pekerjaan.
\end{abstract}

Kata kunci: Keberfungsian butir diferensial, respons tipuan, kepribadian lima faktor.

\begin{abstract}
This study aimed to identify items on psychological scale vulnerable to faking responses when it is applied to the employee selection process. Personality scale adaptation of BFI-44 was given to 400 respondents that were divided into two groups. The first group was instructed to respond honestly (neutral condition) while the second group was instructed them as if they are applicants who are follow employee selection test (applicants condition). Differential item functioning (DIF) test with Mantel-Haenzel test was employed. Analysis result suggests that 12 items are vulnerable to faking response that is spread out on four personality factors (extroversion factor, agreeableness, emotional stability and openness to new ideas). Considering on small number of items that indicates DIF, we conclude that measurement of psychological that use selfreporting technique is resistant to faking responses. However, review thoroughly or modification of these items when applied to the job selection process was required.
\end{abstract}

Kaywords: Differential item functioning, faking response, five factors personality.

\section{PENDAHULUAN}

Penggunaan skala psikologi sebagai salah satu instrumen pengukuran dalam berbagai bidang psikologi telah banyak dilakukan. Penelitian terbaru menunjukkan tingginya frekuensi penggunaan instrumen psikologis dalam banyak lingkup aktivitas, misalnya dalam bidang industri dan organisasi dikarenakan tingginya daya prediksi hasil pengukuran terhadap performansi kerja individu (Meyer, Foster, \& Anderson, 2006). Namun demikian, masih terdapat beberapa masalah yang perlu diatasi untuk meningkatkan kualitas pengukuran psikologi, salah satunya adalah masalah respons tipuan. Hasil pengukuran psikologi akan kurang memprediksi performansi kinerja jika subjek yang diukur memiliki motivasi-motivasi tertentu yang menyebabkan mereka memberikan respons tipuan.

Penelitian menunjukkan bahwa pengukuran psikologi yang berbentuk skala psikologi dengan format pelaporan diri, baik kuesioner atau inventori rentan terhadap respons tipuan. Individu dapat dengan sengaja meningkatkan skor untuk menunjukkan kesan positif/baik mengenai profil kepribadian mereka (Nguyen, Biderman, \& McDaniel, 2005). Hasil analisis protokol verbal yang dilakukan oleh Robie, Brown, dan Beaty (2007) untuk mengeksplorasi motivasi pelamar pekerjaan menunjukkan bahwa pelamar cenderung memberikan respons menipu saat mereka mengisi skala. Dari dua belas pelamar yang mereka teliti, tiga orang terbukti memberikan respons tipuan setelah hasil pengukuran yang dilakukan diverifikasi lebih lanjut melalui analisis kualitatif.

Penelitian lain juga menunjukkan bahwa sejumlah pelamar memalsukan respons mereka terhadap instrumen yang diberikan. Sekitar 30 hingga 50 persen pelamar dapat meningkatkan skor pengukuran psikologi mereka ketika melamar pekerjaan (Griffith, Chmielowski, \& Yoshita, 2007). Dari ukuran efek analisis diperlihatkan bahwa respons tipuan mem- 
berikan peranan yang cukup besar terhadap skor perolehan dari pengukuran faktor keuletan bekerja. Namun, ketika respons tipuan tidak dilakukan ukuran efek tersebut nilainya kecil. Dampak respons tipuan terhadap penurunan validitas empirik alat ukur dilaporkan oleh Komar, Brown, Komar, dan Robie (2008). Melalui studi Monte Carlo mereka menemukan bahwa validitas empirik alat ukur dapat menurun secara signifikan akibat adanya respons tipuan.

Dilaporkan oleh sebuah penelitian bahwa validitas skor menurun dari 0 hingga 33 persen yang tergantung dari tingginya korelasi antara tingkat respons tipuan dengan skor pengukuran faktor ketekunan bekerja. Semakin tinggi korelasi tersebut semakun menurun validitas prediksi pengukuran ketekunan bekerja. Penelitian lain juga menunjukkan bahwa pengukuran kepribadian (e.g. NEO-FFI) sangat rentan terhadap respons tipuan meskipun terjadi pada faktor keuletan, ekstraversi dan neurotisisme (Furnham, 1997). Hasil penelitian tersebut menunjukkan bahwa responden dapat memprediksi skor hasil pengukuran yang dilakukan kepada mereka.

Meskipun banyak penelitian yang menyimpulkan rendahnya ketahanan skala psikologi terhadap respons tipuan, namun ada beberapa penelitian yang menyimpulkan hasil berbeda. Penelitian McDaniel, dkk. (2009) misalnya, menemukan bahwa pada pengukuran kepribadian lima faktor, faktor keuletan tahan terhadap respons tipuan namun sebaliknya tidak pada faktor ekstraversi. Hasil analisis menunjukkan tidak ditemukannya perbedaan skor pengukuran faktor keuletan antara responsen yang diminta memberikan respons jujur dan yang diinstruksikan memberikan respons tipuan. Kondisi yang berbeda ditemukan pada faktor ekstraversi yang menghasilkan perbedaan yang signifikan antar kedua kondisi (jujur dan menipu). Temuan tersebut sama dengan hasil penelitian yang dilakukan oleh Peterson, Griffith, dan Converse (2009) yang menemukan bahwa faktor keuletan yang dikombinasikan dengan pengukuran kemampuan kognitif tahan terhadap respons tipuan. Hasil analisis yang dilakukan menunjukkan bahwa kombinasi dua pengukuran tersebut dapat mereduksi skor yang mengandung respons tipuan sebesar 13.50 persen. Peneliti tersebut menyimpulkan bahwa perubahan skor akibat adanya respons tipuan tidak begitu besar sehingga daya guna pengukuran kepribadian masih besar.

Penelitian Hogan et al. (2007) mengukur 5.266 orang pelamar yang pernah gagal dalam proses seleksi pekerjaan. Instrumen yang dipakai mengukur adalah skala kepribadian lima faktor. Hasilnya 5,2 persen partisipan mengalami peningkatan skor dari pengukuran pada proses seleksi sebelumnya dan hanya tiga orang yang mengalami peningkatan di atas rentang penerimaan 95 persen. Selain itu peneliti juga menemukan bahwa indeks ketepatan pemodelan persamaan struktural menghasilkan nilai ketepatan model yang tidak berbeda antara pengukuran pertama dan kedua. Ketepatan model yang sama tersebut disebabkan oleh rendahnya nilai perbedaan antara partisipan penelitian (yang diasumsikan memberikan respons jujur) dan partisipan yang melamar pekerjaan (yang diasumsikan memberikan respons menipu). Rendahnya perbedaan tersebut terlihat dari ukuran efek (Cohen's- $d$ ) yang menjelaskan adanya perbedaan antar kedua partisipan tersebut sangat kecil (0.01 hingga 0.15). Penelitian ini menunjukkan bahwa instrumen pengukuran psikologi tahan terhadap respons tipuan.

Berbagai strategi untuk mereduksi kerentanan skala psikologi terhadap respons tipuan dilakukan oleh para peneliti sebelumnya, misalnya eksplorasi bentuk respons dalam bentuk pilihan ganda (Jackson, Wroblewski, \& Ashton, 2000), penggunaan skala pendeteksi respons tipuan (Brown \& Harvey, 2003), modifikasi penyekoran skala psikologis menjadi model ipsatif (Saville \& Wilson, 1991), modifikasi penulisan butir (Widhiarso \& Suhapti, 2009) atau melengkapi pengukuran dengan menggunakan biodata (Sisco \& Reilly, 2007). Dari berbagai strategi tersebut, modifikasi penulisan butir lebih praktis dilakukan dibanding dengan strategi lainnya. Bentuk pilihan ganda belum terbukti efektif menekan jumlah penipu; penggunaan skala pendeteksi respons kurang berfungsi karena mengukur keunikan respons individu dan bukan respons tipuan; pengukuran ipsatif hanya dapat dikomparasikan pada konteks intra-individual dan penggunaan biodata dinilai kurang valid karena memproyeksikan masa lalu individu. Untuk memodifikasi butir dibutuhkan masukan model butir seperti apa yang tahan terhadap tipuan. Oleh karena itu, penelitian ini mengeksplorasi butir yang tahan terhadap tipuan dari skala yang sudah banyak dipakai (i.e. BFI-44).

Prosedur penelitian yang dipakai oleh peneliti tersebut adalah menggunakan studi kuasi eksperimental dengan memodifikasi situasi yang dialami partisipan. Situasi yang dibangun adalah (1) situasi netral, yaitu situasi yang umumnya terkait dengan proses penelitian yang hasilnya tidak berdampak secara langsung pada partisipan karena anonimitas mereka tetap terjaga, (2) situasi seleksi, yaitu seakanakan partisipan sedang mengikuti seleksi pekerjaan sehingga harus menunjukkan performansi mereka secara optimal agar diterima dalam pekerjaan yang dilamar, dan (3) situasi peringatan, yaitu melaksanakan pengukuran namun memberikan peringatan 
bahwa di dalam alat ukur yang diberikan terdapat butir-butir skala yang dapat mendeteksi respons tipuan. Skor hasil pengukuran pada ketiga situasi tersebut kemudian dibandingkan untuk melihat ketahanan instrumen pengukuran terhadap respons tipuan. Penelitian-penelitian yang dilakukan menunjukkan bahwa prosedur ini mampu mengungkap seberapa jauh ketahanan pengukuran psikologi terhadap respons tipuan (Thumin \& Barclay, 1993). Dengan dasar tersebut maka penelitian ini mengadopsi desain ini akan tetapi tidak melibatkan situasi ketiga.

Teknik analisis statistika yang biasa dipakai untuk menguji ketahanan pengukuran psikologi terhadap respons tipuan pada prosedur di atas adalah perbandingan selisih skor dalam subjek (Birkeland, Manson, Kisamore, Brannick, \& Smith, 2006), uji perbandingan rerata skor antar subjek (Ortner, 2004) dan aplikasi teori respons butir (Eid \& Zickar, 2007). Dari ketiga teknik analisis tersebut, teknik yang berbasis teori respons butir lebih menghasilkan informasi yang lebih komprehensif karena menekankan pada skor laten daripada skor empirik. Penelitian ini mengaplikasikan pengujian keberfungsian butir diferensial (differential item functioning/DIF) yang berbasis pada teori respons butir. Fokus studi diarahkan pada mendeteksi butir-butir mana di dalam skala yang terjangkit DIF, dalam hal ini butir yang terjangkit DIF adalah butir yang tidak tahan terhadap respons tipuan. Secara teoritik butir yang terjangkit DIF adalah butir yang memberikan peluang besar kepada salah satu kategori individu untuk mendapatkan skor yang tinggi. Sesuai dengan desain yang dipaparkan pada bagian di depan, kategori yang dibandingkan adalah responden yang dikondisikan untuk memberikan respons jujur dan respons tipuan.

\section{METODE PENELITIAN}

\section{Prosedur Penelitian}

Jenis penelitian ini adalah penelitian eksperimen kuasi yang menggunakan model antar-subjek (between-subject). Bentuk manipulasi yang diberikan adalah jenis instruksi, yaitu antara instruksi kepada responden untuk menjawab jujur pada satu kelompok responden dan instruksi menjawab motivatif pada kelompok responden lainnya. Setelah responden dibagi menjadi dua kelompok, masing-masing kelompok mendapatkan skala ukur yang sama namun berbeda instruksi. Instruksi pada kelompok pertama adalah dengan meminta responden merespons setiap butir skala sesuai dengan apa yang dialami dan dirasakan (kelompok jujur). Instruksi pada kelompok kedua adalah dengan meminta responden seakanakan berada dalam situasi seleksi kerja. Oleh karena itu peneliti memperbolehkan responden merekayasa responsnya agar berpeluang untuk lolos dalam tes tersebut.

\section{Responden}

Responden penelitian penelitian ini adalah mahasiswa Fakultas Psikologi UGM. Jumlah responden adalah 400 orang yang dipilih dengan menggunakan teknik pengambilan sample purposif (non acak). Dari jumlah tersebut, 200 orang masuk dalam kelompok 1 dan sisanya masuk dalam kelompok 2. Responden yang tidak lengkap dalam memberikan respons pada butir alat ukur tidak dilibatkan dalam analisisi. Usia responden memiliki usia antara 19 hingga 23 yang berasal dari berbagai daerah di Indonesia. Isian inform consent diberikan sebelum responden berpartisipasi dalam penelitian dan tidak ada responden yang menolak untuk mengikuti penelitian ini.

\section{Instrumen}

Instrumen yang dipakai untuk mengukur adalah Inventori Kepribadian Lima Faktor yang diadaptasi oleh peneliti dari Big Five Inventory (BFI) yang dikembangkan oleh John, Donahue, \& Kentle (1991). Instrumen ini menggunakan model skala Likert yang terdiri dari lima alternatif respons. Cara pengukurannya adalah pelaporan mandiri (self report) yang meminta subjek untuk merespon butir-butir pernyataan menggambarkan berbagai karakteristik individu. Respon yang disediakan ada lima alternatif respons dari sangat setuju hingga sangat tidak setuju dengan penyekoran butir bergerak dari 1 hingga 5 . Skala ini mengukur lima faktor kepribadian antara lain ekstraversi (extroversion), keramahan (agreeableness), ketelitian (conscentiousness), neurotisisme (neuroticism) dan keterbukaan (openess).

Penyekoran butir pada faktor neurotisisme dalam penelitian ini dilakukan secara terbalik sehingga semakin tinggi skor faktor ini menunjukkan semakin tinggi kestabilan emosi subjek. Prosedur ini sesuai dengan pernyataan John, Donahue, \& Kentle (1991) yang mengatakan bahwa penyekoran BFI pada faktor neurotisisme dapat dilakukan secara terbalik. BFI versi Bahasa Indonesia telah diujicobakan oleh peneliti pada sampel mahasiswa $(\mathrm{N}=185)$ yang menghasilkan koefisien reliabilitas alpha sebagai berikut ekstraversi (0.839), keramahan (0.789), keuletan (0.924), kestabilan emosi (0.848) dan keterbukaan (0.807). Hasil ini mirip versi asli yang dilaporkan oleh 
John dan Srivastava BFI memiliki reliabilitas $(\alpha)$ antara 0.75 hingga 0.80 dan reliabilities tes-tes ulang antara 0.80 hingga 0.90 . Validitas BFI pada versi asli yang dikorelasikan dengan NEO-FFI dan TDA menghasilkan rata-rata korelasi sebesar 0.83 hingga 0.91 (John \& Srivastava, 1999).

\section{Teknik Analisis Data}

Data penelitian dianalisis dengan menggunakan pemodelan Rasch yang merupakan bagian dari pendekatan teori respons butir. Setelah dilakukan pemodelan ketepatan parameter butir dengan data yang tersedia, identifikasi keberfungsian butir diferensial dilakukan. Teknik uji yang dipakai untuk menguji adalah uji Mantel-Haenzel. Program lunak yang dipakai untuk menganalisis adalah Winstep 3.

\section{HASIL ANALISIS DAN PEMBAHASAN}

\section{Deskripsi Data}

Deskripsi data secara statistik menunjukkan bahwa skor faktor kepribadian dari kelompok aplikan lebih tinggi dibanding kelompok netral (lihat Tabel 1).
Tabel 1 juga menunjukkan perbandingan antara skor dari distribusi hipotetik dan empirik. Distribusi hipotetik didapatkan dari skala. Misalnya pada faktor ekstraversi, dengan jumlah 8 butir dan skor butir yang bergerak antara 1 hingga 5 maka skor minimal yang dapat diperoleh 8 ( 1 x 8 butir) dan skor maksimal yang dapat diperoleh adalah 40 (5 x 8 butir). Dari perbandingan tersebut terlihat bahwa ada responden yang dapat mencapai skor maksimal pada kondisi netral dan kondisi aplikan. Hasil ini menunjukkan bahwa responden pada kedua kondisi memiliki peluang yang sama untuk mendapatkan skor maksimal.

Dari perbandingan antar rerata skor melalui uji-t didapatkan bahwa selisih tersebut signifikan dengan hasil sebagai berikut. Faktor ekstraversi $(\mathrm{t}=\mathrm{p}<0.01)$, keramahan $(\mathrm{t}=\mathrm{p}<0.01)$, ketekunan $(\mathrm{t}=\mathrm{p}<0.01)$, kestabilan emosi $(\mathrm{t}=\mathrm{p}<0.01)$, dan keterbukaan $(\mathrm{t}=\mathrm{p}$ $<0.01)$.

\section{Uji Keberfungsian Butir Diferensial}

Hasil analisis uji keberfungsian butir diferensial menemukan adanya beberapa butir yang terjangkit DIF. Ada 3 butir pada faktor ekstraversi terjangkit

Tabel 1. Deskripsi Skor Pengukuran antar Kondisi

\begin{tabular}{|c|c|c|c|c|c|c|c|c|}
\hline \multirow[b]{2}{*}{ Kondisi } & \multirow{2}{*}{$\begin{array}{l}\text { Faktor } \\
\text { Kepribadian }\end{array}$} & \multirow{2}{*}{$\begin{array}{l}\text { Jumlah } \\
\text { Butir }\end{array}$} & \multicolumn{2}{|c|}{ Distribusi Hipotetik } & \multicolumn{4}{|c|}{ Distribusi Empiris } \\
\hline & & & $\begin{array}{l}\text { Skor } \\
\text { Minimal }\end{array}$ & $\begin{array}{l}\text { Skor } \\
\text { Maksimal }\end{array}$ & $\begin{array}{l}\text { Skor } \\
\text { Minimal }\end{array}$ & $\begin{array}{l}\text { Skor } \\
\text { Maksimal }\end{array}$ & Rerata & SD \\
\hline \multirow[t]{5}{*}{ Netral } & Ekstraversi & 8 & 8 & 40 & 11 & 40 & 27.90 & 5.02 \\
\hline & Keramahan & 9 & 9 & 45 & 21 & 45 & 35.09 & 4.21 \\
\hline & Ketekunan & 9 & 9 & 45 & 16 & 45 & 30.59 & 5.06 \\
\hline & Kestabilan Emosi & 8 & 8 & 40 & 12 & 34 & 23.56 & 4.06 \\
\hline & Keterbukaan & 10 & 10 & 50 & 17 & 49 & 36.70 & 4.83 \\
\hline \multirow[t]{5}{*}{ Aplikan } & Ekstraversi & 8 & 8 & 40 & 19 & 40 & 31.71 & 4.57 \\
\hline & Keramahan & 9 & 9 & 45 & 27 & 45 & 37.84 & 4.22 \\
\hline & Ketekunan & 9 & 9 & 45 & 20 & 45 & 36.37 & 5.71 \\
\hline & Kestabilan Emosi & 8 & 8 & 40 & 12 & 40 & 25.68 & 6.21 \\
\hline & Keterbukaan & 10 & 10 & 50 & 28 & 49 & 39.21 & 4.29 \\
\hline
\end{tabular}

Tabel 2. Butir dan Hasil Uji Maentel-Haenzel

\begin{tabular}{llllllllll}
\hline $\begin{array}{l}\text { Butir } \\
\text { Fak-1 }\end{array}$ & MH & $\begin{array}{l}\text { Butir } \\
\text { Fak-2 }\end{array}$ & MH & $\begin{array}{l}\text { Butir } \\
\text { Fak-3 }\end{array}$ & MH & $\begin{array}{l}\text { Butir } \\
\text { Fak-4 }\end{array}$ & MH & $\begin{array}{l}\text { Butir } \\
\text { Fak-5 }\end{array}$ & MH \\
\hline 1 & 0.22 & 2 & -0.31 & 3 & -0.02 & 4 & -0.14 & 5 & $0.63^{*}$ \\
6 & 0.05 & 7 & 0.34 & 8 & -0.23 & 9 & $-0.30^{*}$ & 10 & 0.18 \\
11 & $0.43^{*}$ & 12 & -0.23 & 13 & 0.05 & 14 & 0.16 & 15 & $0.51^{*}$ \\
16 & $-0.29^{*}$ & 17 & -0.18 & 18 & 0.10 & 19 & -0.05 & 20 & 0.31 \\
21 & -0.21 & 22 & -0.11 & 23 & 0.07 & 24 & -0.15 & 25 & $0.71^{*}$ \\
26 & -0.08 & 27 & -0.29 & 28 & 0.00 & 29 & -0.09 & 30 & -0.27 \\
31 & 0.10 & 32 & 0.00 & 33 & 0.03 & 34 & 0.04 & 35 & $-1.77^{*}$ \\
36 & $-0.25^{*}$ & 37 & $0.41^{*}$ & 38 & -0.29 & 39 & $0.74^{*}$ & 40 & $0.63^{*}$ \\
& & 42 & $0.29^{*}$ & 43 & 0.23 & & & 41 & -0.30 \\
\end{tabular}

Keterangan: Butir yang diberi tanda $(*)$ adalah butir yang terjangkit $\mathrm{DIF}(\mathrm{p}<0.05)$ 
DIF, 2 butir pada faktor keramahan, 2 butir pada faktor kestabilan emosi dan 5 butir pada faktor keterbukaan (lihat Tabel 2).

Setelah butir-buir yang terjangkit DIF diidentifikasi, langkah selanjutnya adalah memaparkan muatan indikator (item content) tersebut (Tabel 3). Tabel tersebut menunjukkan bahwa butir-butir yang terjangkit DIF mengukur indikator yang terkait dengan pekerjaan. Misalnya pada butir ekstraversi indikator seberapa jauh individu memiliki kapasitas energi untuk bekerja dan kemampuan menghidupkan suasana ketika berinteraksi dengan rekan kerja rentan terhadap respons tipuan. Diskusi mengenai indikatorindikator ini akan dipaparkan pada bagian pembahasan.

Tabel 3. Indikator Pengukuran yang Terjangkit DIF

\begin{tabular}{lll}
\hline $\begin{array}{l}\text { Faktor } \\
\text { Kepribadian }\end{array}$ & No. Indikator yang diukur \\
\hline Ekstraversi & 11 & Energi \\
& 16 & Kemampuan menghidupkan \\
& & suasana \\
Keramahan & 36 & Minat kerjasama \\
& 37 & Perilaku sopan \\
Kestabilan Emosi & 42 & Minat bekerjasama \\
& 39 & Kemampuan mengatasi tekanan \\
Keterbukaan & 5 & Keunikan pribadi \\
& 15 & Pemikiran \\
& 25 & Kreatifitas \\
& 35 & Minat terhadap variasi pekerjaan \\
& 40 & Menindaklanjuti gagasan baru \\
\hline
\end{tabular}

\section{Pembahasan}

Penelitian ini bertujuan mengidentifikasi butir skala psikologi yang rentan terhadap respons tipuan ketika diaplikasikan pada seleksi pekerjaan. Dari analisis ditemukan adanya beberapa butir yang rentan terhadap respons tipuan. Pada faktor ekstraversi yang mengukur indikator terkait keaktifan, kegairahan, keaktif berbicara, kerjasama dan kemampuan mengekspresikan emosi positif (McRae \& Costa, 2003) ternyata memuat dua indikator yang rentan terhadap respons tipuan. Penelitian menunjukkan bahwa individu yang memiliki ekstraversi tinggi sangat dibutuhkan pada jenis pekerjan yang luas karena terkait dengan jiwa kepemimpinan (Lim \& Ployhart, 2004). Individu yang memiliki kapasitas kepemimpinan, seperti aktif, energik dan proaktif dinilai lebih mendukung kesuksesan dalam bekerja. Secara luas juga dikenal dalam teori-teori kepemimpinan bahwa karyawan yang miliki karakteristik kepemimpinan yang efektif, seperti percaya diri dan komunikatif sangat diperlukan pada pekerjaan umum (Manning \& Curtis, 2002).
Selain ekstraversi faktor lain yang banyak memuat butir yang rentan respons tipuan adalah keterbukaan terhadap ide. Beberapa penelitian menunjukkan bahwa konstruk keterbukaan terhadap ide yang terkait dengan penghargaan terhadap kreativitas, minat terhadap estetika, imajinasi, intelektual dan gagasan baru (Bing \& Lounsbury, 2000), dibuktikan memiliki kaitan dengan pekerjaan yang dipersepsi responden penelitian ini. Sama seperti ekstraversi, indikator faktor keterbukaan terkait dengan bidang pekerjaan luas, terutama pekerjaan yang membutuhkan penalaran dan eksplorasi ide-ide baru (Caldwell \& Liu, 2011). Banyak perusahaan yang mendukung adanya perubahan organisasional untuk menyesuaikan dengan tuntutan masyarakat. Oleh karena itu mereka membutuhkan pekerja-pekerja yang kreatif, inovatif dan bersikap positif terhadap perubahan. Alasan inilah yang dipakai oleh responden pada kelompok aplikan berusaha meningkatkan skornya pada faktor keterbukaan (Smollan, Matheny, \& Sayers, 2010).

Sedikitnya butir yang terjangkit DIF pada faktor keramahan dan kestabilan emosi dapat disebabkan oleh rendahnya keterkaitan faktor tersebut dengan pekerjaan. Faktor keramahan mengukur seberapa individu ideal dalam kaca mata sosial sedangkan faktor kestabilan emosi mengukur kemampuan individu untuk mengatasi ketegangan. Kedua faktor ini dinilai responden kurang terkait dengan pekerjaan karena dinilai memberikan sumbangan yang kecil terhadap performansi bekerja, padahal beberapa penelitian membuktikan hal sebaliknya. Misalnya kestabilan emosi dinilai terkait dengan kedisiplinan kerja (Roehling, 1999).

Hasil yang kontradiktif terlihat pada tidak adanya butir pada faktor ketelitian yang dalam banyak penelitian dibuktikan terkait dengan performansi karyawan (Furnham, 1997). Hal ini dapat terjadi karena responden memiliki strategi khusus dalam memberikan respons tipuan. Pada butir-butir lain mereka memberikan respons tipuan akan tetapi pada butir lain tidak dilakukan karena sudah dilakukan pada butir sebelumnya. Adanya strategi ini mengindikasikan bahwa responden tidak mencoba untuk meningkatkan skornya pada semua butir hingga mencapai skor maksimal, akan tetapi mencoba mengembangkan profil tertentu yang cocok dengan profil pekerjaan yang ditawarkan.

\section{KESIMPULAN}

Penelitian ini menemukan beberapa butir skala psikologi yang rentan terhadap respons tipuan. Butirbutir tersebut tersebar dalam empat faktor kepribadian 
dengan proporsi sebesar 27 persen dari keseluruhan butir. Dengan proporsi tersebut secara umum menunjukkan bahwa pengukuran psikologi yang menggunakan teknik pelaporan mandiri (self-report) cukup tahan terhadap respons tipuan. Namun demikian tetap perlu diadakan tinjauan ulang atau modifikasi terhadap butir-butir tersebut.

\section{DAFTAR PUSTAKA}

Bing, M.N. \& Lounsbury, J.W., 2000, Openness and Job Performance in U.S.-Based Japanese Manufacturing Companies. Journal of Business and Psychology, 14(3), pp. 515-522.

Birkeland, S.A., Manson, T.M., Kisamore, J.L., Brannick, M.T. \& Smith, M.A., 2006, A metaanalytic investigation of job applicant faking on personality measures. International Journal of Selection and Assessment, 14(4), pp. 317335.

Brown, R.D. \& Harvey, R.J., 2003, Detecting Personality Test Faking with Appropriateness Measurement: Fact or Fantasy? Paper presented at the Annual Conference of the Society for Industrial and Organizational Psychology, Orlando.

Caldwell, S.D. \& Liu, Y., 2011, Further investigating the influence of personality in employee response to organisational change: the moderating role of change-related factors. Human Resource Management Journal, 21(1), pp. 7489. doi: 10.1111/j.1748-8583.2010.00127.x

Eid, M., \& Zickar, M. J. (2007). Detecting response styles and faking in personality and organizational assessments by mixed rasch models. New York: Springer.

Furnham, A.F., 1997, Knowing and Faking One's Five-Factor Personality Score, Journal of Personality Assessment, 69(1), pp. 229-243.

Griffith, R.L., Chmielowski, T. \& Yoshita, Y., 2007, Do applicants fake? An examination of the frequency of applicant faking behavior. Personnel Review, 36(3), pp. 341-355.

Hogan, J., Barrett, P. \& Hogan, R., 2007, Personality measurement, faking, and employment selection. Journal of Applied Psychology, 92(5), pp. 1270-1285.

Jackson, D.N., Wroblewski, V.R. \& Ashton, M.C., 2000, The Impact of Faking on Employment Tests: Does Forced Choice Offer a Solution? Human Performance, 13(4), pp. 371-388.

John, O.P., Donahue, E.M. \& Kentle, R.L., 1991, The Big Five Inventory-Versions $4 a$ and 54. California: University of California, Berkeley, Institute of Personality and Social Research.
John, O.P. \& Srivastava, S., 1999, The big five trait taxonomy: History, measurement, and theoretical perspectives. In L. A. Previn \& O. P. John (Eds.), Handbook of personality: Theory and research (2nd ed). New York: Guilford Press.

Komar, S., Brown, D.J., Komar, J.A. \& Robie, C., 2008, Faking and the validity of conscientiousness: A Monte Carlo investigation. [doi: 10.1037/0021-9010.93.1.140]. Journal of Applied Psychology, 93(1), 140-154. doi: 10. 1037/00219010.93.1.140

Lim, B.C. \& Ployhart, R.E., 2004, Transformational leadership: Relations to the five-factor model and team performance in typical and maximum contexts. Journal of Applied Psychology, 89(4), pp. 610-621.

Manning, G. \& Curtis, K., 2002, The art of leadership. New York: McGraw-Hill International.

McDaniel, M.J., Beier, M.E., Perkins, A.W., Goggin, S. \& Frankel, B., 2009, An assessment of the fakeability of self-report and implicit personality measures. Journal of Research in Personality, 43, 3.

McRae, R.R. \& Costa, P.T., 2003, Personality in adulthood: A five-factor theory perspective. New York: The Guilford Press.

Meyer, K.D., Foster, J. \& Anderson, M.G., 2006, Assessing the predictive validity of the performance improvement characteristics job analysis tool. Paper presented at the 21th Annual Conference OF Society for Industrial and Organizational Psychology, May 2006, Dallas, Texas.

Nguyen, N.T., Biderman, M.D. \& McDaniel, M., 2005, Effects of response instructions on faking a situational judgment test. International Journal of Selection and Assessmen, 13(4), 250-260. doi: 10.1111/j.1468-2389.2005. 00322.x

Ortner, T.M., 2004, On changing the position of items in personality questionnaires Analysing effects of item sequence using IRT. Psychology Science, 46(4), pp. 466-476.

Peterson, M.H., Griffith, R.L. \& Converse, P.D., 2009, Examining the role of applicant faking in hiring decisions: percentage of fakers hired and hiring discrepancies in single and multiplepredictor selection. Journal of Business and Psychology.

Robie, C., Brown, D. \& Beaty, J., 2007, Do people fake on personality inventories? A verbal protocol analysis. Journal of Business and Psychology, 21(4), pp. 489-509. 
Roehling, M.V., 1999, Weight-Based Discrimination In Employment: Psychological and Legal Aspects. Personnel Psychology, 52(4), 9691016. doi: 10.1111/j.1744-6570.1999.tb00186.x

Saville, P. \& Wilson, E., 1991, The reliability and validity of normative and ipsative approaches in the measurement of personality. Journal of Occupational Psychology, 64, pp. 219-238.

Sisco, H. \& Reilly, R.R., 2007, Five Factor Biodata Inventory: resistance to faking. Psychological Reports, 101(1), pp. 3-17.

Smollan, R.K., Matheny, J.A. \& Sayers, J.G., 2010, Personality, affect, and organizational change: a qualitative study. In J.Z. Wilfred, C.E.J.
Härtel \& N.M. Ashkanasy (Eds.), Emotions and Organizational Dynamism (Research on Emotion in Organizations, Volume 6). Bingley, UK: Emerald Group Publishing Limited.

Thumin, F.J. \& Barclay, A.G., 1993, Faking behavior and gender differences on a new personality research instrument. [doi:10.1037/1061-4087. 45.4.11]. Consulting Psychology Journal: Practice and Research, 45(4), 11-22. doi: 10.1037/ 1061-4087.45.4.11

Widhiarso, W. \& Suhapti, R., 2009, Eksplorasi karakteristik item skala psikologis yang rentan terhadap tipuan respon. Jurnal Psikologi, 36(1), pp. 73-91. 